\title{
Communication use in the times of the coronavirus. A cross-cultural study
}

\author{
Juan-José Igartua; Félix Ortega-Mohedano; Carlos Arcila-Calderón
}

Nota: Este artículo se puede leer en español en:

http://www.elprofesionaldelainformacion.com/contenidos/2020/may/igartua-ortega-arcila_es.pdf

How to cite this article:

Igartua, Juan-José; Ortega-Mohedano, Félix; Arcila-Calderón, Carlos (2020). “Communication use in the times of the coronavirus. A cross-cultural study". El profesional de la información, v. 29, n. 3, e290318.

https://doi.org/10.3145/epi.2020.may.18

Article received: $14-05-2020$

Definitive acceptance: $22-05-2020$

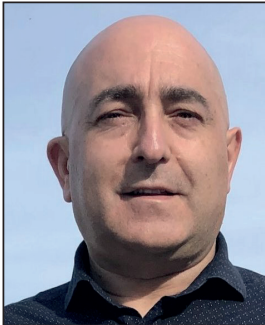

Juan-José Igartua $\measuredangle$

http://orcid.org/0000-0002-9865-2714

Universidad de Salamanca

Dto. de Sociología y Comunicación

Avda. Francisco Tomás y Valiente

Campus Unamuno, Edificio FES

37007 Salamanca, Spain

jigartua@usal.es

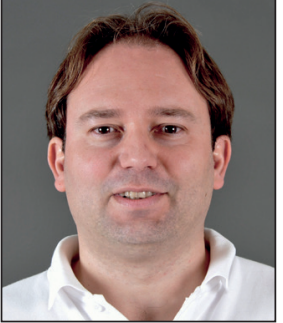

Félix Ortega-Mohedano

http://orcid.org/0000-0003-2735-4813

Universidad de Salamanca

Facultad de Ciencias Sociales

Avda. Francisco Tomás y Valiente

Campus Unamuno, Edificio FES

37007 Salamanca, Spain

fortega@usal.es

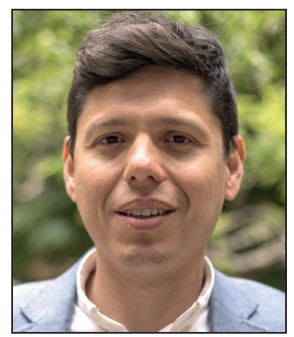

\section{Carlos Arcila-Calderón \\ http://orcid.org/0000-0002-2636-2849 \\ Universidad de Salamanca \\ Facultad de Ciencias Sociales \\ Avda. Francisco Tomás y Valiente \\ Campus Unamuno, Edificio FES \\ 37007 Salamanca, Spain \\ carcila@usal.es}

\begin{abstract}
The results of an online cross-cultural survey conducted from mid-March to mid-April 2020 in various countries $(N=789)$ are presented. The theoretical basis of this work is uses and gratifications theory. This work provides a novel contribution regarding communication use in the context of the coronavirus pandemic. The results indicate that the consumption of information about the coronavirus is structured along four latent dimensions: (a) specialized health information on the Internet, official websites, and obtained through health personnel; (b) through "visual" social media; (c) through "written" social media and face-to-face contacts; and (d) through the mass media. Significant differences are found in all the dimensions of consumption depending on age and country of residence. Furthermore, it is observed that high consumption of information about the coronavirus increases perceived knowledge on the subject, which in return leads to the adoption of preventive measures. The present work provides a first snapshot of communication use in the face of the coronavirus pandemic crisis and provides a portrait of the behavior of communication users in the month immediately after the declaration of the Covid-19 pandemic worldwide. It can be concluded that communication has played a fundamental role in transmitting preventive information in the face of the coronavirus crisis.
\end{abstract}

\section{Keywords}

Covid-19; SARS-CoV-2; Coronavirus; Pandemics; Preventive behavior; Media consumption; Uses and gratifications; Media use; Exposure conditions; Cross-cultural survey; Factor analysis; Mediation analysis; Process.

Acknowledgements

Firstly, the authors are grateful to all those anonymous people who made it possible for this research to be carried out by spreading and sharing the questionnaire via their social networks. We also thank the following people for their translation work and coding of the questionnaire: Chiara Dello lacono (translation), Maximiliano Frías Vázquez (coding), Derval Gomes Golzio (translation), Wenrun Li (coding), and Tian Zhao (translation). 


\section{Introduction}

The situation created by the coronavirus (SARS-CoV-2) in recent months has resulted in changes of a magnitude incomparable to other uncertain scenarios that society has had to face at a global level. Three of the most notable characteristics of the Covid-19 are its rapid transmission, highly contagious nature (high Ro), and high case fatality rate, especially in older people and/or those with preexisting health problems.

https://www.who.int/health-topics/coronavirus\#tab=tab_1

All of these factors led to the declaration of a pandemic by the World Health Organization (WHO) on 11 March 2020 . As a result, the emergence of this virus has changed the daily life of citizens on practically all the continents.

This article presents the results of a cross-cultural online survey that was carried out from mid-March to mid-April 2020. The present work analyzes the consumption of information about the coronavirus to discover the latent structure of these practices. The main aim is to determine how the consumption of information about the coronavirus has occurred, namely which means or sources have been used to seek information about the virus. The theoretical framework of this study is based on uses and gratifications theory (Rubin, 2009a; 2009b). In this regard, the present work does not seek only to provide a descriptive portrait of how the consumption of information about the coronavirus has occurred, but also to verify the dimensional structure of such consumption of information, as well as to analyze the differences in these latent dimensions depending on gender, age, and country of residence.

In addition, the effects of information consumption on the adoption of preventive practices are also analyzed. In this sense, it is assumed as a working hypothesis that the consumption of information about the coronavirus could have had a positive indirect effect on the adoption of preventive measures aimed at slowing the pandemic, thanks to the fact that consumption of information itself can increase perceived knowledge about the disease, influencing the perception of its severity as well as people's mood. These factors (mediators) could explain the (indirect) effect of the consumption of information about the coronavirus on the adoption of preventive behaviors. Finally, this research also provides theoretical reflections on the role of traditional and social media in scenarios of high uncertainty such as that faced since the arrival of Covid-19 in our lives.

\section{The uses and gratifications of communication}

Uses and gratifications theory is one of the classical theories of communication (Katz; Blumer; Gurevitch, 1973). In its origins, it arised as a reaction to the "theories of incitement," which only studied media effects (Igartua; Humanes, 2004). The research problems that can be addressed using this theory are based on one premise: one of the fundamental characteristics of media communication is its ability to capture people's free time. Within the study of the mass media, it becomes a fundamental theoretical tool to analyze how, when, and why people spend time consuming media content, to the point that it colonizes their free time (Rubin, 2009a; Krcmar, 2017; Scherer, 2017). For this reason, a large portion of the research carried out from this perspective (with a clear psychological orientation) is based on the study of uses, motives for exposure (as motives identified by individuals to explain their media consumption), needs, expectations, involvement, and media dependency (Rubin, 2009b).

Although classical studies have focused on the uses and motives of the mass media such as radio, the press, or television, this theoretical perspective has been perfectly adapted to the new communication ecosystem (Igartua; Humanes, 2004). Existing empirical works have focused on the use of the Internet (LaRose; Eastin, 2004; Papacharissi; Rubin, 2000), mobile phones (Leung; Wei, 2000), video games (González-Vázquez; Igartua, 2018; Sjöblom; Hamari, 2017), and various social networks (Bae, 2018; Ezumah, 2013; Korhan; Ersoy, 2016; Phua; Jin; Kim, 2017). The field of analysis of social networks has expanded to include specific works on the uses and motives for using Facebook (Igartua; Rodríguez-de-Dios, 2016), WhatsApp (Karapanos; Teixeira; Gouveia, 2016), Instagram (Sheldon; Rauschnabel; Antony; Car, 2017), Twitter (Chen, 2011), and YouTube (Khan, 2017).

One of the conclusions reached in these studies is that the different media in the communication ecosystem (mass media, and social media, in particular) offer clearly differentiated communication opportunities that address the uses, motivations, and expectations related to each of them. For example, the "like" culture is strongly associated with social networks such as Facebook, Instagram, and YouTube, which encourage the promotion of the self (Sheldon et al., 2017), the capture of "followers," and so-called "posturing" (Daries-Ramón; Ferrer-Rosell; Cristóbal-Fransi; Mariné-Roig, 2018; Hossain; Kim; Jahan, 2019; Vizcaíno-Laorga; Catalina-García; López-de-Ayala-López, 2019). However, this effect does not occur with social media such as WhatsApp or Twitter, whose consumption prioritizes written messages, the expression of opinions, and dialog-based interactions (Chen, 2011; Karapanos; Teixeira; Gouveia, 2016; Phua; Jin; Kim, 2017). 


\section{Communication use in the coronavirus era}

We believe that the uses and gratifications theoretical approach is applicable as a focus for studies on communication use in relation to the coronavirus. In particular, in our work we apply the term "communication use," taking as a reference the definition of media use (Scherer, 2017), which can be considered to be one of the leading concepts of this theoretical perspective, perhaps together with the concept of motive for exposure. The concept of media use (communication use) refers to all kinds of activity that involves contact with media, messages, and media content, and that facilitates exposure to certain information. However, exposure conditions (Igartua, 2015) can vary in terms of intensity and the quality of information processing, differentiating between the automatic, attentional, transported, and self-reflective states (for a review, see Potter, 2013).

The attentional state implies that the user is aware of the message and actively interacts with the elements of the information. This occurs when an individual pays attention to a news broadcast on the radio or when a person is engaged in reading a report in a newspaper. There is great elasticity in this state, depending on the degree of concentration that the person pays to each detail of the content that is being consumed.

There may also be situations in which media is consumed in "autopilot mode" (the automatic state), in which the person exposed to the message is not aware of all its details, leading to unconscious processing of many elements. This state of exposure occurs when browsing a magazine in a waiting room; in divided attention situations, such as watching television while chatting with family; or in multitasking situations, such as watching a news program on television while at the same time using social networks.

The transported state also involves concentrating attention on the message in a conscious way, but to a point that the individual feels literally engaged and becomes part of the narrated story, thereby being transported from their reality into that created symbolically by the message. Such a transported user leaves their own world for a few moments to become emotionally involved in the media world to which they are exposed. This state, which is highly characteristic of the consumption of narrative messages, involves putting oneself into the shoes of another person and feeling their emotions. During recent months, since the start of the coronavirus outbreak (which later became a pandemic), people have witnessed numerous first-person stories narrating dramatic situations caused by the virus, sometimes involving healthcare personnel (Fig. 1) or by people affected by the situation (Fig. 2).

https://www.youtube.com/watch?v=ht4MamjXZgM

Finally, the self-reflective state implies being (hyper)aware of one's exposure to the message, but unlike the previous state, intense cognitive processing occurs and the individual is able to monitor their reactions to it. That is, in this case, the individual is not only aware that they are paying attention to the message, but also about how they are interpreting it. In this way, the individual monitors their own reactions to the message and can ask themselves: Why am I exposing myself to this content? Why am I interpreting it in this way? Therefore, this results in not only an analysis of the message but also a kind of meta-analysis (Igartua, 2015).

In short, when we refer to the concept of media use, we are considering a broad concept linked to exposure to communication content but that can vary in both intensity and quality. Differential communication use is characteristic of modern societies, in which it is observed that people are in contact with the media and social networks for more than $70 \%$ of their waking time (Potter, 2013). It is thus logical to assume that not all communication uses will lead to highly involved exposure states.

This is the context in which this work is carried out: not only seeking to analyze the consumption of information about the coronavirus, but to trace the possible conse-

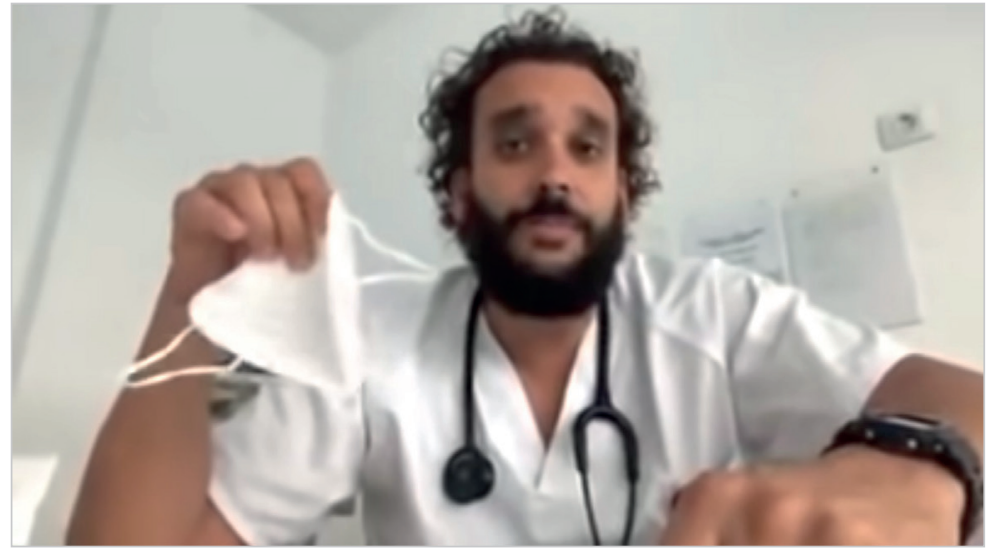

Figure 1. Advice to government experts https://www.youtube.com/watch?v=gIP6J7zDICg

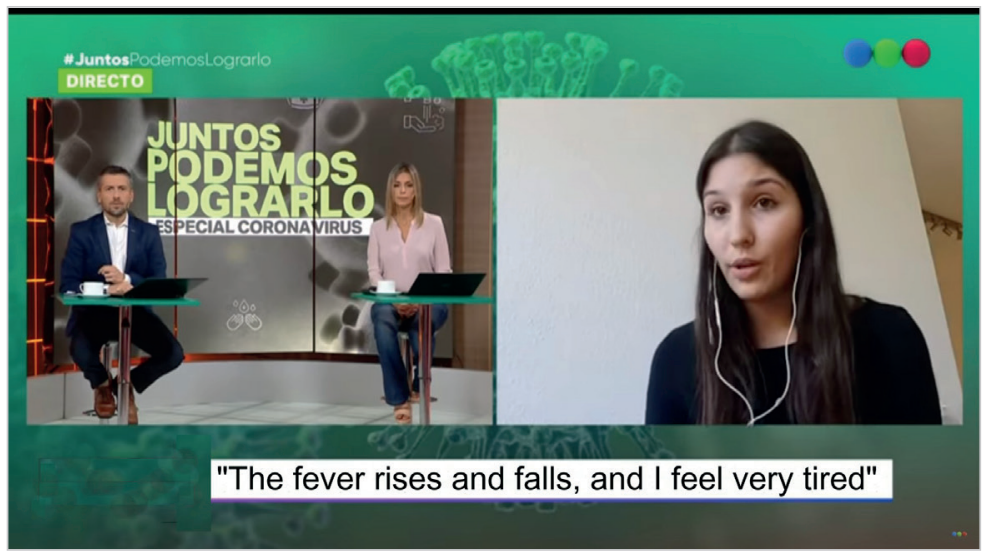

Figure 2. A first-person story of the coronavirus

https://www.youtube.com/watch?v=ht4MamjXZgM 
quences that such communication use has been able to have in terms of the acquisition of knowledge about the coronavirus, the perception of the severity of the disease, the impact on affective processes (mood), and preventive behaviors.

A nonsystematic analysis of the information about the coronavirus that has been disseminated by different media and social networks ${ }^{1}$, leads us to conclude that, in recent months, the emphasis has been on the risks of the disease (its symptoms, the health problems it causes, and the high probability of accidental infec-

tion), the most vulnerable populations, the figures on deaths and new infections, the collapse of the health system due to the increase in infections, and of course preventive measures. Therefore, it can be expected that high consumption of information about the coronavirus will cause an increase in perceived knowledge about the disease, an increase in the perception of its severity, as well as an increase in worry that will impact on mood. Furthermore, it is assumed that these factors may, in turn, impact on the adoption of preventive measures. However, it is not possible to guess which factor(s) will be most relevant to trigger preventive behaviors.

The cognitive pathway approach explains the impact of the consumption of information about the coronavirus on preventive behaviors, assuming that the underlying mechanism is the improvement of perceived knowledge. However, one can also propose a second route via the activation of the perception of severity: the consumption of information will activate the perception of severity, which, in turn, would lead people to act more cautiously. Finally, the affective route would explain the impact of consuming information on preventive behaviors due to the role of mood, considering that affective discomfort would lead to healthy behaviors because they would help to comfort people. Therefore, the proposed mediation model contemplates three mediating mechanisms acting in parallel, and our analysis enables an empirical determination of which mechanism(s) is (are) the most relevant (Fig. 3).

\section{Methods}

\subsection{The sample and procedures}

An online survey was conducted using Qualtrics (adopting a cross-sectional design), being available from 16 March to 20 April 2020. For this, an anonymous brief questionnaire $\left(M_{\text {duration }}=9.52\right.$ minutes, $\left.S D=19.93\right)$ was prepared and disseminated to a heterogeneous population on social networks (Facebook, Twitter, and WhatsApp), as well as to researchers by email, academic mailing lists (Communication, by RedIris), and international scientific associations, viz. the International Communication Association (ICA) and European Communication Research and Education Association (ECREA):

https://www.rediris.es/list/info/comunicacion.html

https://www.icahdq.org

https://ecrea.eu

A nonprobabilistic sampling strategy was adopted using snowball sampling, meaning that, when sharing the questionnaire online through social networks and email, those who completed it were also encouraged to pass it on to their contacts, family, and friends (Baxter; Babbie, 2004).

Five versions of the questionnaire were created in different languages depending on their distribution: the Spanish version was disseminated in Spain and various Latin American countries (with Spanish as an official language), the Portuguese version was distributed exclusively in Brazil, the Italian version was distributed only in Italy, and the Chinese version in China, while the English version was global in scope. In this way, a total sample (after cleaning up the dataset) of 789 people residing in 26 countries was obtained, although the majority lived in Spain $(n=349)$, China $(n=128)$, Brazil $(n=95)$, Italy $(n=74)$, Ecuador $(n=49)$, the USA $(n=27)$, and Mexico $(n=22)$.

A total of 533 women (67.6\%), 252 men (31.9\%), and 4 others $(0.5 \%$, who selected "another option" on the question on gender) participated in the survey. The mean age of the respondents was 39.40 years $(S D=$ $14.70)$, ranging from 15 to 78 years old. Given that Qualtrics provides information on the exact date on which each questionnaire was completed, it was observed that $12.2 \%$ of people answered the survey between 16 and
When we refer to the concept of media use, we are considering a broad concept linked to exposure to communication content that can vary in both intensity and quality 
22 March, 16.7\% between 23 and 29 March, 20.47\% between 30 March and 5 April, 44\% between 6 and 12 April, and $6.5 \%$ between 13 and 20 April.

The questionnaire was organized in six blocks and comprised previously validated scales (on mood), questions used in previous studies, and measures created ad hoc given the novelty of the studied phenomenon. Block 1 (introduction) contained the title ("Survey on the perception of the coronavirus"), the objectives of the study, and the informed consent. Block 2 (sociodemographic data) asked about gender, age, and country of residence. Block 3 included a measure of affectivity or mood. Block 4 (information about the coronavirus) collected information on the perceived knowledge and consumption of information about the coronavirus by different means. Block 5 included an open-ended question to collect information on the adoption of effective preventive measures for personal protection and to prevent the spread of the coronavirus. Block 6 included a question about the perception of the severity of the coronavirus.

\subsection{Measures}

Mood. A standardized scale called the Positive and Negative Affect Schedule (Panas), originally developed by Watson, Clark, and Tellegen (1988), was used to assess mood. The Panas scale is made up of 20 emotional terms, grouped into two dimensions of positive affectivity (for example, enthusiastic, inspired, and proud) and negative affectivity (for example, distressed, worried, and irritable), with respondents being asked to indicate the extent to which they have experienced these feelings and emotions during a certain time interval: in the present study, the interval used was "at this time" ("indicate the extent to which you feel that way at this time," from 1 for "slightly or not at all" to 5 for "extremely"). Three indicators were constructed from the obtained scores: positive affect $(\mathrm{M}=2.77, \mathrm{SD}=0.60)$, negative affect $(\mathrm{M}=2.24, \mathrm{SD}=$ $0.78)$, and affective balance, calculated as the difference between the positive and negative affects $(M=0.52$, $\mathrm{SD}=0.94)$. The affective balance index was used as an indicator to evaluate the mood of the participants, with higher scores reflecting better mood. Note that the validated Spanish (Sandín; Chorot; Lostao; Joiner; Santed; Valiente, 1999), Portuguese (Galinha; Pais-Ribeiro, 2005; Galinha; Pereira; Esteves, 2014; Pires; Filgueiras; Ribas; Santana, 2013), and Italian (Terracciano; McCrae; Costa, 2003) versions of this scale were used in the current study, with satisfactory reliability values for the indicators of positive and negative affect being obtained in all the countries in which the survey was administered (Table 1).

Table 1. The reliability of the positive and negative affect scales (Cronbach's alpha) by country of residence of the respondents

\begin{tabular}{|l|c|c|c|}
\hline $\begin{array}{l}\text { Country of } \\
\text { residence }\end{array}$ & $\boldsymbol{N}$ & Positive affect & $\begin{array}{c}\text { Negative } \\
\text { affect }\end{array}$ \\
\hline Spain & 349 & .77 & .89 \\
\hline China & 128 & .76 & .89 \\
\hline Brazil & 95 & .68 & .86 \\
\hline Italy & 74 & .68 & .87 \\
\hline Ecuador & 49 & .76 & .91 \\
\hline USA & 27 & .79 & .84 \\
\hline Mexico & 22 & .79 & .89 \\
\hline Other country & 72 & .84 & .87 \\
\hline
\end{tabular}

Perceived knowledge about the coronavirus. Taking as a reference a previous study conducted in the USA (McFadden; Malik; Aguolu; Willebrand; Omer, 2020), perceived knowledge was measured using a single-item question: "How would you rate your knowledge about the coronavirus?" (from 1 for "very low" to 5 for "very high"; $M=3.49, S D=0.72$ ).

Consumption of information about the coronavirus. Respondents were asked "to what extent have you been informed about the coronavirus through the following means?", offering 15 different types of media adapted to the country of distribution of the questionnaire: television, radio, press (newspapers), magazines, internet searches (through Google or similar), the website of the Spanish Ministry of Health, Consumer Affairs, and Social Welfare, the website of the World Health Organization (WHO), websites of medical organizations, healthcare professionals (in health centers, hospitals, etc.), face-to-face conversations (with friends, family, colleagues, or classmates), WhatsApp (Wechat in China), Twitter (Weibo in China), Instagram (Douyin, TikTok, in China), YouTube (Youku in China), and Facebook (QQ in China). For each medium, the intensity of information consumption was to be indicated on a five-point scale, from 1 for "not at all" to 5 for "very much" (the mean and standard deviation for each type of media are presented in Table 2).

Perception of severity of the coronavirus. This was measured using a scale made up of six items (for example, "I believe that the coronavirus is more serious than the flu" and "my health will be seriously damaged if I contract the coronavirus," from 1 for "strongly disagree" to 7 for "strongly agree"). This scale was constructed from a scale made up of 10 items that had been used in a survey carried out by McFadden et al. (2020) in the USA and which demonstrated adequate reliability $(\alpha=.71)$. However, in this study, the indicator created by calculating the average of the six items exhibited lower reliability $(\alpha=.57 ; M=4.76, S D=0.85)$.

Preventive behaviors. As an indicator of preventive behavior, an innovative procedure was chosen: using an open-ended question, respondents were asked "In your opinion, what are the most effective measures to protect yourself and prevent the spread of the coronavirus?" The responses to this open-ended question were coded using a system of preventive behavior categories previously established based on WHO recommendations:

https://www.who.int/en/emergencies/diseases/novel-coronavirus-2019/advice-for-public/qa-coronaviruses 
Table 2. Principal-components factor analysis (varimax rotation) of the coronavirus information consumption scale

\begin{tabular}{|c|c|c|c|c|c|}
\hline \multirow{2}{*}{ Consumption of information about the coronavirus through ... } & \multirow{2}{*}{$M(S D)$} & \multicolumn{4}{|c|}{ Factor } \\
\hline & & $\mathbf{F 1}$ & F2 & F3 & F4 \\
\hline WHO website & $2.45(1.40)$ & .84 & & & \\
\hline Websites of medical organizations & $2.35(1.29)$ & .83 & & & \\
\hline Ministry of Health website & $2.79(1.41)$ & .75 & & & \\
\hline Health professionals (in health centers, etc.) & $2.37(1.35)$ & .58 & & & \\
\hline Internet searches (through Google or similar) & $3.40(1.32)$ & .45 & .40 & & \\
\hline Facebook [QQ in China] & $2.22(1.34)$ & & .71 & & \\
\hline YouTube [Youku in China] & $1.82(1.14)$ & & .70 & & \\
\hline Instagram [Douyin, TikTok, in China] & $1.85(1.24)$ & & .63 & .31 & \\
\hline Face-to-face conversations (with friends, family, etc.) & $3.01(1.19)$ & & & .72 & \\
\hline WhatsApp [Wechat in China] & $2.96(1.38)$ & & .35 & .70 & \\
\hline Twitter [Weibo in China] & $2.43(1.54)$ & & & .63 & \\
\hline Press (newspapers) & $2.72(1.41)$ & & & & .74 \\
\hline Radio & $2.16(1.28)$ & & & & .70 \\
\hline Magazines & $1.65(1.01)$ & .37 & & & .57 \\
\hline Television & $3.22(1.25)$ & & & & .49 \\
\hline Percentage of variance explained & & 22.67 & 13.83 & 10.16 & 7.02 \\
\hline Cronbach's Alpha & & .77 & .57 & .55 & .52 \\
\hline Mean ( $1=$ not at all, $5=$ very much $)$ & & 2.67 & 1.96 & 2.80 & 2.43 \\
\hline Standard deviation & & 0.44 & 0.22 & 0.31 & 0.68 \\
\hline
\end{tabular}

Note: Only factor loads equal to or greater than .30 are included.

(1) wash your hands thoroughly and frequently, (2) maintain personal distances, social distancing, (3) avoid touching your eyes, nose, and mouth, (4) cover your mouth and nose, use of masks, (5) stay at home if you are not feeling well, (6) stay informed about the latest news regarding Covid-19, (7) check the latest news about the most dangerous areas, and (8) isolation, confinement, quarantine, and staying at home. The answers provided by the respondents were coded based on whether each of these preventive measures was mentioned (score 1) or not (score 0 ). This indicator created to measure preventive behavior thus gives values from 0 for "low" to 8 for "high" adoption of preventive behaviors (M $=1.77, \mathrm{SD}=1.17)$.

Table 3. Preventive measures mentioned when answering the open-ended question "In your opinion, what are the most effective measures to protect yourself and prevent the spread of the coronavirus?"

\begin{tabular}{|l|c|}
\hline Preventive measure & Mentioned (\%) \\
\hline 1. Wash your hands thoroughly and frequently & 38.4 \\
\hline 2. Maintain personal distances, social distancing & 24.6 \\
\hline 3. Avoid touching your eyes, nose, and mouth & 3.4 \\
\hline 4. Cover your mouth and nose, use of masks & 26.5 \\
\hline 5. Stay at home if you are not feeling well & 7.0 \\
\hline 6. Stay informed about the latest news regarding Covid-19 & 12.4 \\
\hline 7. Check the latest news about the most dangerous areas & 1.6 \\
\hline 8. Isolation, confinement, quarantine, stay at home & 63.5 \\
\hline
\end{tabular}

\section{Results}

\subsection{Factor structure regarding the consumption of information about the coronavirus}

A factor analysis (principal component analysis, with Varimax rotation) was carried out on the coronavirus information consumption scale. The analysis extracted four factors that together explained $53.83 \%$ of the variance. The Kaiser-Meyer-Olkin (KMO) measure of adequacy was .77, and Bartlett's sphericity test was statistically significant $\left(\chi^{2}(107)=\right.$ $2500.41, p=.001$ ), confirming the quality and adequacy of the results of this analysis (Table 2). The first factor contained the sources of information related to the consumption of health information through trustworthy medical sources and specific Internet searches. The second factor grouped social media that have a more visual profile and are associated 
with "posturing." The third factor grouped social media with a more pronounced "written" component and face-to-face interpersonal communication. And the fourth factor grouped the traditional mass media. Based on this structure, four indicators of the consumption of information about the coronavirus were created, revealing that, overall, the respondents were exposed with greater intensity through "written" social media $(M=2.80, S D=0.31)$ and, to a lesser extent, through "visual" social media $(M=1.96, \mathrm{SD}=0.22)$.

\subsection{Effects of gender and age on the consumption of information about the coronavirus}

The Pearson correlation coefficient was applied to analyze the relationship of gender and age with the four dimensions of consumption of information about the coronavirus. The results showed that gender was only associated with the consumption of information through "visual" social media, which was higher for men than women (Table 4). In contrast, age showed statistically significant associations with all the dimensions of the consumption of information about the coronavirus: for younger age, greater consumption of specialized health information was observed on the Internet, official websites, and through health personnel, and through both "visual" and "written" social media. However, consumption of information through the mass media (television, press, radio, and magazines) was greater among older people. These results show that age is a more decisive factor than gender in explaining the differences in the consumption of information about the coronavirus.

Table 4. Pearson's correlations of gender and age with the consumption of information about the coronavirus

\begin{tabular}{|l|c|c|}
\hline \multicolumn{1}{|c|}{ Consumption of information about the coronavirus through... } & Gender \\
\hline Internet searches, specialized websites, and healthcare personnel & -.02 & $-.14 * * *$ \\
\hline Through "visual" social media & $-.21 * * *$ \\
\hline Through "written" social media & -.00 & .00 \\
\hline Through the mass media & $.30 * * *$ \\
\hline N & 785 \\
\hline
\end{tabular}

Note: Gender $\left(0=\right.$ male, $1=$ female). Information consumption $\left(1=\right.$ not at all, $5=$ very much). ${ }^{* *} p<.01, * * * p<.001$.

\subsection{Differences in consumption of information about the coronavirus according to country of residence}

A multivariate analysis of variance (manova) revealed statistically significant differences in the consumption of information about the coronavirus according to the country of residence of the respondents (Wilks' Lambda $=.43, F(28,2806.54$ ) $=26.27, p=000, \eta_{p}^{2}=.189$ ). At the univariate level, statistically significant differences were also observed, depending on the country of residence, in the consumption of specialized health information on the Internet, official websites, and through healthcare personnel $\left(F(7,781)=8.80, p=.000, \eta_{p}{ }^{2}=.073\right)$, in consumption through "visual" social media ( $F(7$, $\left.781)=20.56, p=.000, \eta_{p}{ }^{2}=.156\right)$, in consumption through "written" social media $\left(F(7,781)=42.26, p=.000, \eta_{p}{ }^{2}=.275\right)$, and in consumption through the mass media $\left(F(7,781)=24.53, p=.000, \eta_{p}^{2}=.18\right)$.

These results indicate, firstly, that the maximum differences between countries are observed in the variables describing the consumption through "written" social media (with the country of residence explaining $27.5 \%$ of the variance) and the mass media (with the country variable explaining $18 \%$ of the variance). The second aspect that this analysis highlights is that, in all countries, except Spain (and China), the main origin of information about the coronavirus was through specialized health sources and Internet searches. Thirdly, respondents from Spain were (along with residents in "other countries") those who consumed the most information through the mass media (see Fig. 4). And fourthly, citizens residing in China consumed the most information about the coronavirus through "written" social media and face-to-face contacts, although this result is probably explained by the fact that respondents from that country were younger. ( $M=25.68, S D=6.60)$ than residents in other countries ( $\mathrm{M}_{\text {global }}$ $=39.30, \mathrm{SD}=14.70$ ) while age was negatively associated with the consumption of information through social media, as mentioned above..

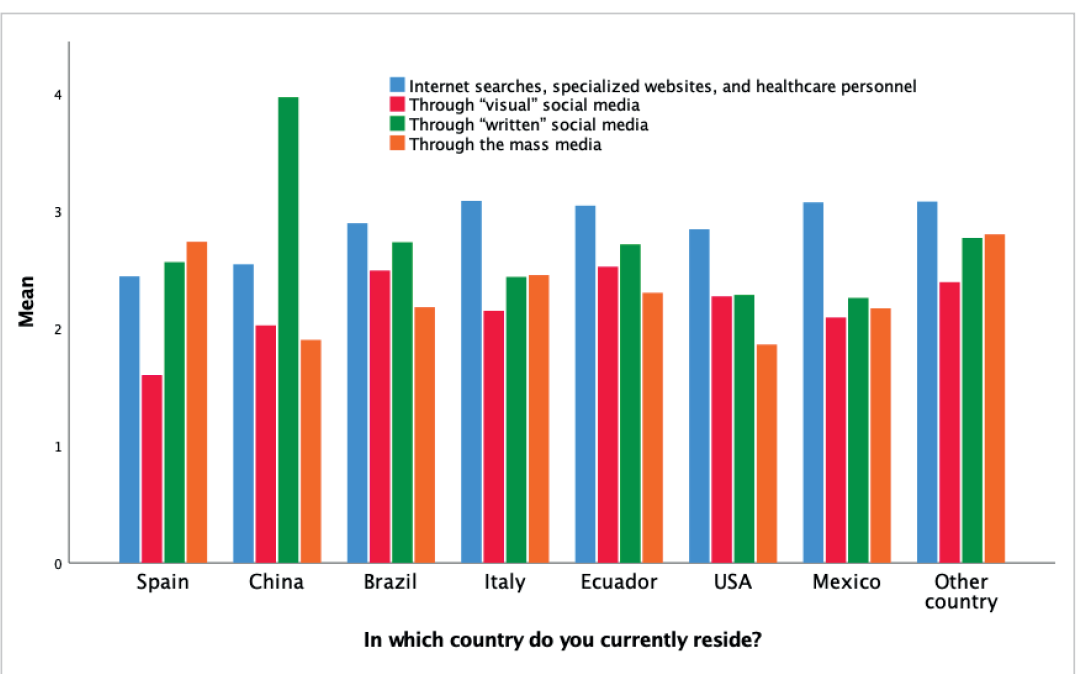

Figure 4. Differences of means in the consumption of information about the coronavirus according to country of residence 


\subsection{Consequences of consuming information about the coronavirus}

To determine the possible consequences of consuming information about the coronavirus, four multiple linear regression analyses were carried out. The aim was to determine the specific influence of each type of information consumption on four relevant variables: the degree of perceived knowledge about the coronavirus, the perceived severity of the disease, the mood of the respondents, and the adoption of preventive measures. In these analyses, gender ( 0 for "male," 1 for "female"), age, and country of residence (coded as 1 for "Spain" and 0 for "other countries") were included as control variables.

The first model showed that the variables considered were significantly associated with the perceived knowledge about the coronavirus and that $13 \%$ of their variance was explained $(R=.37, F(7,777)=18.59, p=.000)$. Regardless of the influence of $\operatorname{sex}(\theta=-.05, p=.087)$, age $(B=.13, p=.000)$, and country of residence $(b=$ $-.20, p=.000)$, it was observed that the consumption of specialized health information on the Internet, official

The cognitive pathway approach can be used to explain the impact of consumption of information about the coronavirus on preventive behaviors, assuming that the underlying mechanism is improvement of perceived knowledge websites, and through health personnel $(B=.22, p=.000)$ and the consumption of information through "written" social media and face-to-face contacts $(B=.22, p=.000)$ were associated with higher perceived knowledge about the coronavirus. Moreover, greater consumption of information through "visual" social media was associated with lower perceived knowledge $(\beta=-.11, p=.004)$, whereas the consumption of mass media was not significantly related to this variable ( $\theta$ $=.02, p=.563)$.

The second regression model was also statistically significant $(R=.28, F(7,777)=9.86, p=.000)$, explaining $7 \%$ of the variance in the perceived severity of the coronavirus. Controlling for the effect of $\operatorname{sex}(B=.00, p=.991)$, age $(B=0.19, p$ $=.000)$, and country of residence $(\beta=-.10, p=.014)$, it was observed that the consumption of specialized health information on the Internet, official websites, and through health personnel was not associated with the perceived severity of the disease $(B=.0 .04, p=.198)$. However, the consumption of information through "written" social media and face-to-face contacts $(B=.12, p=.001)$, through "visual" social media $(\theta=.10, p=.013)$, and through the mass media $(b=$ $.09, p=.013$ ) was associated with higher perceived severity.

Mood (affective balance) was statistically associated with the considered variables, explaining $5 \%$ of the variance $(R=$ $.24, F(7,777)=7.23, p=.000)$. Meanwhile, the only information consumption variable that was associated with mood was the consumption of information through "written" social media and face-to-face contact, revealing a positive relationship $(B=.11, p=.003)$.

Finally, the predictive model of the adoption of preventive measures in the face of the coronavirus was also statistically significant $(\mathrm{R}=.14, \mathrm{~F}(7,777)=2.39, p=.020)$. However, the percentage of variance explained was much lower than in the previous models (1\%), implying that there are other, much more relevant variables than those considered here to explain the degree of adoption of preventive measures among the respondents. In any case, it was observed that,

Table 5. Consequences of consuming information about the coronavirus. Multiple regression analysis

\begin{tabular}{|c|c|c|c|c|c|c|c|c|}
\hline \multirow[t]{2}{*}{ Criterion variables } & \multicolumn{2}{|c|}{$\begin{array}{l}\text { Perceived } \\
\text { knowledge }\end{array}$} & \multicolumn{2}{|c|}{$\begin{array}{l}\text { Perceived } \\
\text { severity }\end{array}$} & \multicolumn{2}{|c|}{$\begin{array}{l}\text { Mood (affecti- } \\
\text { ve balance) }\end{array}$} & \multicolumn{2}{|c|}{$\begin{array}{l}\text { Preventive } \\
\text { measures }\end{array}$} \\
\hline & 8 & $p$ & b & $p$ & 8 & $p$ & b & $p$ \\
\hline \multicolumn{9}{|l|}{ Predictors } \\
\hline Gender & -.05 & .087 & .00 & 991 & -.13 & .000 & .05 & .125 \\
\hline Age & .13 & .000 & .19 & .000 & .21 & .000 & .13 & .001 \\
\hline Country & -.20 & .000 & -.10 & .014 & -.00 & .852 & -.00 & .902 \\
\hline \multicolumn{9}{|l|}{ Consumption of information about the coronavirus through... } \\
\hline $\begin{array}{l}\text { Internet searches, specialized websites, and healthcare person- } \\
\text { nel }\end{array}$ & .22 & .000 & .04 & .198 & -.02 & .442 & .03 & .444 \\
\hline "Visual" social media & -.11 & .004 & .10 & .013 & -.03 & .378 & .02 & .480 \\
\hline "Written" social media & .22 & .000 & .12 & .000 & .11 & .003 & .05 & .189 \\
\hline The mass media & .02 & .563 & .09 & .013 & -.03 & .410 & -.09 & .014 \\
\hline $\mathrm{F}(g l)$ & \multicolumn{2}{|c|}{$18.59(7,777)$} & \multicolumn{2}{|c|}{$9.86(7,777)$} & \multicolumn{2}{|c|}{$7.23(7,777)$} & \multicolumn{2}{|c|}{$2.39(7,777)$} \\
\hline$p$ & \multicolumn{2}{|c|}{.000} & \multicolumn{2}{|c|}{.001} & \multicolumn{2}{|c|}{.000} & \multicolumn{2}{|c|}{.000} \\
\hline $\mathrm{R}$ (Adjusted R²) & \multicolumn{2}{|c|}{$.37(.13)$} & \multicolumn{2}{|c|}{$.28(.07)$} & \multicolumn{2}{|c|}{$.24(.05)$} & \multicolumn{2}{|c|}{$.14(.01)$} \\
\hline
\end{tabular}

Note: $N=785$. Gender $(0=$ male, $1=$ female $)$. Country $(1=$ Spain, $0=$ other country). Information consumption $(1=$ not at all, $5=$ very much). Perceived knowledge ( 1 = very low, 5 = very high). Perceived severity $(1=$ low, 7 = high). Affective balance (higher score, more positive mood). Preventive measures ( 0 low adoption of preventive behaviors, $8=$ high adoption of preventive behaviors). 
regardless of sex $(\beta=.05, p=.125)$, age $(\beta=$ $.13, p=.001)$, and country of residence $(B=$ $-.00, p=.902)$, the consumption of information through the mass media was associated with lesser adoption of preventive measures (b=-.09, $p=.014)$.

In conclusion, it is observed that the consumption of specialized health information on the Internet, official websites, and through health personnel improves perceived knowledge about the coronavirus. The consumption of information through "visual" social media increases the perception of the severity of the diseases but reduces the perceived knowledge. Consuming information through "written" social media and face-to-face contact increases perceived knowledge about the coronavirus as well as the perception of the severity of the disease, and improves mood. The consumption of information through the traditional mass media increases the perceived severity, but is associated with lesser adoption of preventive measures. In addition, in all the analyses, it is observed that older people showed higher scores on perceived knowledge, perceived severity, and adoption of preventive measures, as well as better affective balance.

The final block of results includes a multiple mediation analysis. Mediation analysis is a multivariate statistical analysis method that enables analysis of the indirect effects of a predictor variable on a certain criterion variable by considering one or more explanatory mechanisms connected in a causal chain (Hayes, 2018). In short, mediation analysis allows one to answer the question of how or why an effect occurs (Igartua, 2006).

As already ventured in the "Introduction" to this article, the proposed mediation model contemplates three mediating mechanisms (acting in parallel), and our analysis allows us to empirically determine which mechanism is more relevant to explain the (indirect) effect of the consumption of information about the coronavirus on the adoption of preventive measures (which acts as a criterion or dependent variable). The mechanisms introduced in the four developed mediation models were: perceived knowledge about the disease, perception of the severity of the coronavirus, and mood (affective balance). Furthermore, gender, age, and country of residence of the respondents were included as control variables.

The most important aspect of mediation analysis is the quantification of the indirect effect. To carry out this analysis, the Process macro for SPSS was used (model 4, parallel mediation; 10,000 boostrapping samples to generate $95 \%$ confidence intervals by the percentile

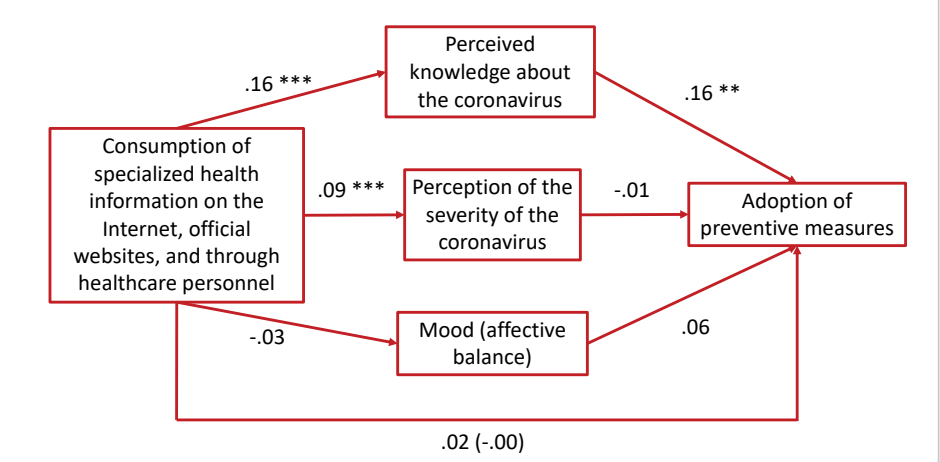

(a) Consumption of specialized health information on the Internet, official websites, and through health personnel (model 1)

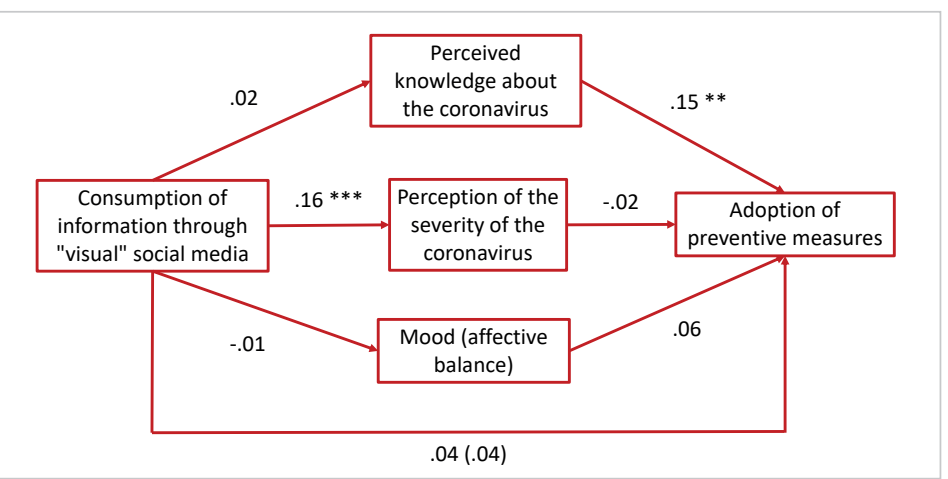

(b) Consumption of information through "visual" social media (model 2)

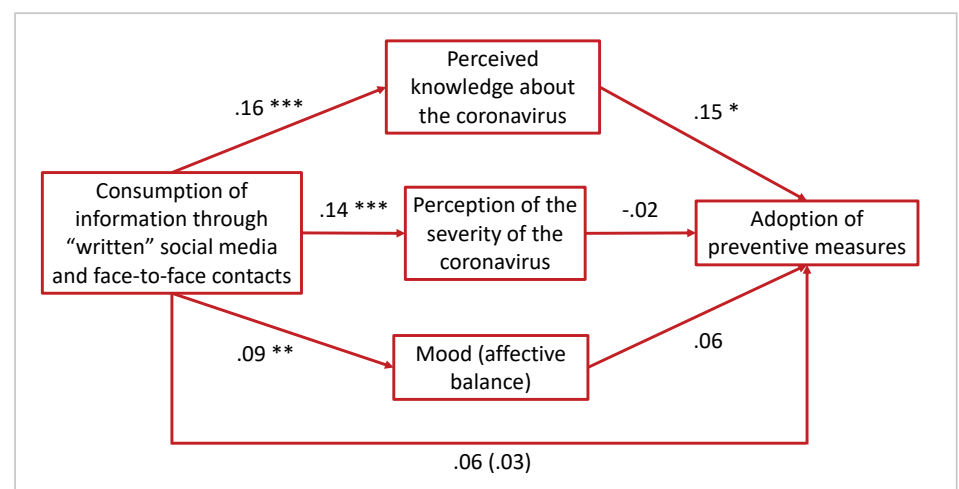

(c) Consumption of information through "written" social media and face-to-face contacts (model 3)

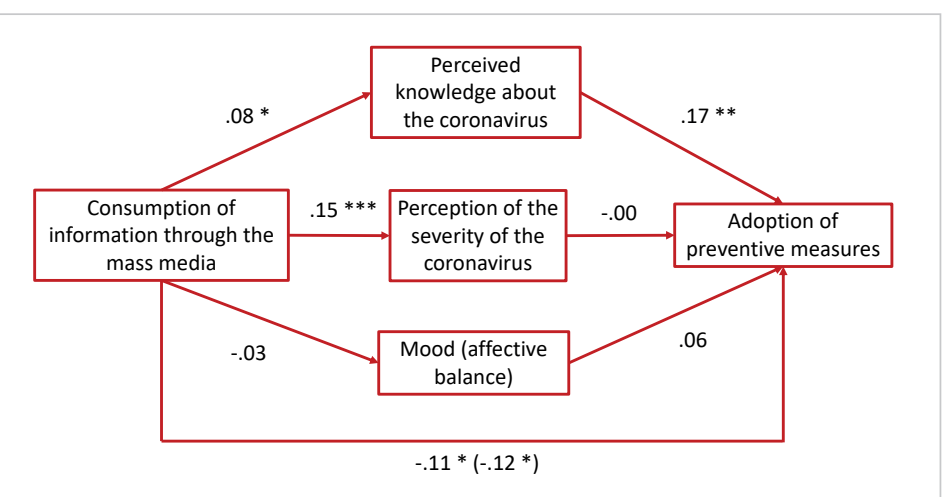

(d) Consumption of information through the mass media (model 4)

Figure 5. Explanatory mechanisms for the effect of consumption of information about the coronavirus on the adoption of preventive measures. Mediation models with Process

Note: Nonstandardized regression coefficients $(B)$ are shown in the figure. In addition, the regression coefficients of the total effect and the direct effect (in parentheses) of the consumption of information about the coronavirus on the adoption of preventive measures are shown. In all the analyses, sociodemographic variables (gender, age, and country of residence) were included as covariates. $N=$ 785. $* p<.05 * *, p<.01, * * * p<.001$. 
method; Hayes, 2018). Process allows the estimation of indirect effects, standard errors (SE), and confidence intervals $(\mathrm{Cl})$ using the bootstrapping technique. In this context, an indirect effect is considered to be statistically significant if the established confidence interval $(\mathrm{Cl}$, at 95\%) does not include the value 0 .

The first mediation model included the consumption of specialized health information on the Internet, official websites, and through healthcare personnel as a predictor variable. The second model included the consumption of information through "visual" social media as a predictor variable. In the third model, the predictor variable was the consumption of information through "written" social media and face-to-face contact. Finally, in the fourth model, the consumption of information through the mass media acted as the predictor variable. The results of these analyses are presented in Table 6 (indirect effects) and in Fig. 5.

The analysis of the indirect effects of the consumption of health information on the Internet, specialized official websites, and through health personnel on the adoption of preventive measures revealed that only the perceived knowledge acted as a mediating mechanism. Thus, greater consumption of information of this type was associated with greater perceived knowledge $(B=.16, p=.000)$, which, in turn, was associated with an increase in preventive behaviors ( $B=.16$, $p=.008)$. Even though exposure to specialized health information increased the perception of severity $(B=.09, p=.001)$, this variable was not associated with the adoption of preventive measures $(B=-.01, p=.727)$.

The second mediation model revealed that consumption of information through "visual" social media did not have any significant indirect effect on the adoption of preventive measures. Although exposure to such information increased the perception of severity $(B=.16, p=.000)$, this variable was not significantly associated with prevention measures $(B=$ $-.02, p=.612)$. On the other hand, consumption of such information did not enhance perceived knowledge $(B=.02, p=$ $.474)$, although this was significantly associated with the adoption of preventive measures $(B=.15, p=.007)$.

Table 6. Indirect effects of consuming information about the coronavirus on the adoption of preventive measures. Mediation models with Process

(a) Consumption of specialized health information on the Internet, official websites, and through health personnel (model 1)

\begin{tabular}{|l|c|c|c|}
\hline \multicolumn{1}{|c|}{ Mediating mechanism } & Indirect effect & Boot SE & Boot 95\% Cl \\
\hline Perceived knowledge & $\mathbf{. 0 2 7 2}$ & $\mathbf{. 0 1 1 4}$ & {$[.0064, .0513]$} \\
\hline Perceived severity & -.0018 & .0054 & {$[-.0128, .0092]$} \\
\hline Affective balance & -.0022 & .0033 & {$[-.0099, .0033]$} \\
\hline
\end{tabular}

(b) Consumption of information through "visual" social media (model 2)

\begin{tabular}{|l|c|c|c|}
\hline \multicolumn{1}{|c|}{ Mediating mechanism } & Indirect effect & Boot SE & Boot 95\% CI \\
\hline Perceived knowledge & .0034 & .0056 & .0085 \\
\hline Perceived severity & -.0043 & {$[-.0069, .0158]$} & .0032 \\
\hline Affective balance & -.0010 & {$[-.00214, .0124]$} & \\
\hline
\end{tabular}

(c) Consumption of information through "written" social media and face-to-face contacts (model 3)

\begin{tabular}{|l|c|c|c|}
\hline \multicolumn{1}{|c|}{ Mediating mechanism } & Indirect effect & Boot SE & Boot 95\% CI \\
\hline Perceived knowledge & $\mathbf{. 0 2 4 5}$ & $\mathbf{. 0 1 0 6}$ & [.0046, .0461] \\
\hline Perceived severity & -.0039 & .0080 & {$[-.0202, .0112]$} \\
\hline Affective balance & .0056 & .0050 & {$[-.0028, .0168]$} \\
\hline
\end{tabular}

(d) Consumption of information through the mass media (model 4)

\begin{tabular}{|l|c|c|c|}
\hline \multicolumn{1}{|c|}{ Mediating mechanism } & Indirect effect & Boot SE & Boot 95\% Cl \\
\hline Perceived knowledge & $\mathbf{. 0 1 4 7}$ & $\mathbf{. 0 0 8 6}$ & [.0014, .0347] \\
\hline Perceived severity & -.0005 & .0083 & .0042 \\
\hline Affective balance & -.0026 & {$[-.0178, .0159]$} \\
\hline
\end{tabular}

Note $N=785$. An indirect effect is considered to be statistically significant if the established $95 \%$ confidence interval (CI) does not include the value 0 . The inclusion of 0 in the confidence interval indicates that the indirect effect is equal to 0 ; that is, there is no association between the variables included in the causal chain (Hayes, 2018). Statistically significant indirect effects are marked in bold. In all the analyses, sociodemographic variables (gender, age, and country of residence) were included as covariates.

The third mediation model yielded results similar to those obtained in the first model. The analysis of the indirect effects of consumption of information through "written" social media and face-to-face contact on the adoption of preventive measures found that only perceived knowledge acted as a mediating mechanism. Thus, greater consumption of information of this type was associated with higher perceived knowledge $(B=.16, p=.000)$, which, in turn, was associated with 
an increase in preventive behaviors $(B=.15, p=.012$ ). Although exposure to information about the coronavirus through "written" social media and face-to-face contact increased the perception of the severity of the disease $(B=.14, p=.000)$, this variable was not associated with the adoption of preventive measures $(B=-.02, p=.618)$. A similar result was found with regard to mood: consumption of information through "written" social media and face-to-face contact improved $\operatorname{mood}(B=.09, p=.007)$, but this affective process was not significantly associated with adopting a greater number of preventive measures $(B=.06, p=.207)$.

Finally, the results of the four mediation models are in accordance with the results of models 1 and 3. Only a statistically significant indirect effect of the consumption of information through the mass media on the adoption of preventive measures was observed. Thus, greater consumption of information about the coronavirus in the mass media was associated with higher perceived knowledge $(B=.08, p=.012)$, which, in turn, was associated with an increase in preventive behaviors $(B=.17, p=.003)$.

\section{Discussion and conclusions}

The present work provides a first snapshot of communication use in the face of the coronavirus crisis. It constitutes a portrait of the communicative behavior of people in the month immediately after the declaration of the global Covid-19 pandemic (on 11 March 2020) by the World Health Organization. The coronavirus represents a social, health, and economic challenge, but it also constitutes an opportunity to study communication use in the face of the uncertainty generated by the pandemic, in a setting of high cognitive dependence on the information circulating in the media (BallRokeach; DeFleur, 1976) and on social networks (Wang; Lee; Hua, 2015).

In this online survey study (with the participation of people from up to 26 countries), it was found that those surveyed had unequal access to different sources of information. Firstly, searching for information through the Internet, consultation of websites with specialized information, and consultation of health professionals at health centers or hospitals constitutes a latent first dimension, as shown by the results of the factor analysis. Likewise, it is verified that the traditional mass media (television, radio, press, and magazines) behave as a single latent dimension. However, social media does not seem to constitute a unified latent dimension. Rather, it is observed that social media can be grouped into two groups: the first consisting of those with a greater visual component, capture of "likes," or even "posturing" (such as Instagram, YouTube, and Facebook) and a second that groups social media where written text takes on greater prominence (such as Twitter) and with a more dialogical component, by facilitating synchronous communication more easily (as happens with WhatsApp). Curiously, face-to-face communication with family, friends, or colleagues was also associated with this last latent dimension. Even alone, these results already allow us to reach a first conclusion: social media is not a homogeneous whole, although this label is usually used to refer to them (Ezumah, 2013; Korhan; Ersoy, 2016; Quan-Haase; Young, 2010). Furthermore, the descriptive information verifies that this latent dimension including "written-dialogical" social media and face-to-face interactions represents the main source that respondents used to inform themselves about the coronavirus. Secondly, the results reveal consumption through specialized health information on the Internet and institutional websites. Again in this dimension, interpersonal communication with health professionals is combined with the consumption of information obtained through more personalized searches on the Internet.

A second conclusion is that gender is not a relevant variable to understand the dynamics of consumption of information about the coronavirus. In fact, a significant difference related to this variable is only observed for the consumption of information about the coronavirus through "visual" social media, which was more prevalent among the surveyed men than women. However, there are clear differences in the intensity of consumption of information about the coronavirus by age. The participants in this study were aged from 15 to 78 years, with an average age of about 40 years. It is verified that the youngest people consumed the most information about the coronavirus through "written-dialogical" social media, "visual" social media, as well as more specialized searches for information on the Internet and health sources. On the other hand, the consumption of information through the more traditional media (television, radio, press, and magazines) increases significantly with respondent age. These results are in accordance with audience data provided by the Association for Media Research (Asociación para la Investigación de Medios de Comunicación, AIMC), which reveal clear differences in the consumption of television, press (newspaper reading), and the Internet, as well as partially in relation to radio, by age.

http://www.aimc.es

The consequences of consuming information about the coronavirus have been analyzed in two ways. First, multiple regression models were applied with the aim of verifying the individual contribution of each source of information to relevant outcome variables, such as perceived knowledge about the coronavirus, the perceived severity of the disease, mood, and the adoption of preventive measures to address the pandemic. These analyses clearly show that the different uses of communication are paired with different consequences. Thus, it is observed that greater consumption of information is associated with higher perceived knowledge about the coronavirus, with the exception of consumption through "visual" social media, which, in fact, is negatively associated with this variable. Furthermore, exposure to information through the mass media also does not contribute to the perception of knowledge about the coronavirus. Another relevant element of these analyses is the observation that the consumption of information is associated with a greater perception of severity. Undoubtedly, the daily release of the figures for the numbers of infections and victims in 
the media, and the alarm resulting in the early stages of the pandemic about the need to "flatten" the curve, are elements that have contributed notably to the increased perception of the severity of the disease. Having said that, consumption of specialized health information on the Internet and institutional websites does not contribute to this increase in the perception of severity, despite the fact that it is associated with greater perceived knowledge of the coronavirus.
Communication has been essential to the transmission of preventive information about the coronavirus, but it is evident that the more "visual" social media (Instagram, Facebook, and YouTube) have not had an impact on prevention

The mediation analysis allowed us to verify the influence of information consumption on the adoption of preventive measures and understand which mechanisms are relevant for this effect to occur. Three possible routes of influence had been hypothesized: the cognitive route (assuming that the consumption of information produces an improvement in perceived knowledge, which would lead to the adoption of preventive practices), the affective route (through the impact of information on mood), and a third route via enhanced perception of severity (whereby the consumption of information would enhance the perception of severity, which would lead people to act more cautiously). The results of our study are in accordance with the first mechanism: a high consumption of information about the coronavirus increases the perceived knowledge on the subject, which in turn leads to the adoption of preventive measures. It can therefore be concluded that communication has played a fundamental role in transmitting preventive information that has been adequately assimilated by the people exposed to it. However, it is also evident that the more "visual" social media (Instagram, Facebook, and YouTube) have not had an impact on prevention.

The present study advances our knowledge about communication use, adopting the theoretical perspective of uses and gratifications (Krcmar, 2017). The term "communication use" has been used, taking as a reference the definition of media use proposed by Scherer (2017). Communication use is understood as a label that refers to media contact and exposure to certain information. However, this implies the suggestion that the motivations associated with consumption, the needs that it seeks to satisfy, and the expectations that each person develops about each medium or source of information are relevant elements for understanding how these uses are produced. Furthermore, it is assumed that users are aware of their motivations, needs, and expectations and therefore that it is possible to measure them using instruments such as questionnaires or interviews.

One of the criticisms that have been made of the uses and gratifications theoretical perspective is that it focuses on the precommunicative phase, thus how people come into contact with communication is described or analyzed, while the processes or mechanisms that occur during the process of communication consumption and that explain the possible effects or consequences of communication are not. Our work also aims to make a contribution in this regard by going beyond verifying how the consumption of information about the coronavirus occurs to model its possible consequences by adding a mediation analysis.

In this sense, our proposal draws, theoretically speaking, on the ideas developed by Valkenburg and Peter (2013). The Differential Susceptibility to Media Effects Model, developed by those authors, provides a general theoretical template that serves as a reference to study the relationship between communication uses and effects, giving great prominence to what happens during exposure to communication. In this work, although we have not been able to analyze this process rigorously, a first attempt is made to try to understand how communication use can be linked to the adoption of preventive measures to deal with the coronavirus, thanks to the activation of a cognitive process (people's perception of their level of knowledge about the virus). In this sense, our work has tried to analyze what those authors define as second-order media effects.

The effects caused by communication use can begin during the information consumption process. For example, exposure to news stories about the number of coronavirus victims is likely to stimulate negative emotions (such as sadness or fear) and this, in turn, influences information recall or the perception of the severity of the illness. It is also possible that the consumption of communication through social networks (for example, through a detailed Twitter follow-up of hashtags such as \#Coronavirus or \#EsteVirusLoParamosUnidos) activates cognitive processes such as cognitive reflection or elaboration and that this, in turn, leads to the generation of a high perception of threat or that one has sufficient knowledge on the subject.

However, the consequences of communication use can also extend beyond the specific situation of use, consumption, or exposure. For example, consuming news about the coronavirus can stimulate face-to-face interpersonal discussion and, in turn, participation in social networks. An analysis of this type has been carried out herein with the aim of determining the consequences of consuming information about the coronavirus for the adoption of collective and individual, preventive and protective measures to address the pandemic. Rather than analyzing how information processing has occurred during its consumption (which cognitive and emotional processes are triggered, for example, when listening to a news item on the subject or reading a message on Twitter), this work has analyzed how a communication product (developing the perception that the knowledge of the coronavirus is high) has been able to influence the adoption of preventive measures, which could therefore be considered a second-order media effect. 
Despite the contributions that we believe our study makes, it also suffers from a number of limitations. First, our work uses a cross-sectional design, through the application of a survey at a particular moment in the development of the pandemic. Given the correlational nature of the study, it is premature to establish a causal sequence between the variables of consumption and prevention, given that an inverse pattern could also occur, i.e., that people with greater awareness, prior knowledge, and preventive behaviors would consume more information about the coronavirus as a way to "update" and "validate" their knowledge and social preventive practices.

Secondly, our main criterion variable, i.e., the adoption of preventive measures, does not constitute a behavioral indicator in itself, but is based on the appreciation of individuals regarding which are the most effective measures to prevent the coronavirus. In this sense, it is striking that the mean of this variable in the group of respondents was so low ( $M=$ $1.77, \mathrm{SD}=1.17$, for a measure with a theoretical range from 0 to 8 ) and, in fact, no respondent obtained a score of 7 or 8 (the maximum being 6 ), while $12.8 \%$ of people did not indicate any preventive measures. This result may be explained by the fact that an open-ended question was used, and perhaps the people only mentioned the measures that they considered most important or were not exhaustive in their answers due to lazy writing. Perhaps different results would have been obtained by using dichotomous closed-ended questions $(0=$ no, $1=$ yes), so that respondents marked the most effective measures to protect themselves and prevent the spread of the coronavirus. However, this approach would also have its disadvantages, since it may activate social desirability bias (of the "good citizen," who claims to do everything well), and it was precisely for this reason that the indirect procedure was chosen (Fisher, 1993).

Thirdly, despite the use of validated measures or those used in previous studies on the coronavirus (McFadden et al., 2020; Wang et al., 2020), we observed that some of the instruments showed low reliability or internal consistency, as occurred with the scale used to evaluate the perception of severity. And, fourthly, as this was an online survey with voluntary participation and snowball sampling, we obtained unequal participation in the different countries in which the questionnaire was distributed, rendering a more relevant cross-cultural comparison infeasible. That is why, in many of the analyses, country of residence was included as a control variable with only two values (resident in Spain versus another country). As this was not a funded project, the possibilities of accessing samples of a similar size in each country were limited.

Despite the above-mentioned limitations, we believe that the present study provides a valuable snapshot, or vignette, of communication use in the times of the coronavirus and the relationships between information consumption and prevention practices in the global Covid-19 pandemic scenario. We have thus observed that a mechanism that can explain the adoption of preventive measures to address the coronavirus has been the activation of a cognitive process (obtaining confidence about the degree of knowledge that people have about the virus) derived from communication use.

\section{Note}

1. Google Scholar searches with the keywords "coronavirus," "Covid-19," "content analysis," and "news media" revealed no studies of this type published to date. For this reason, the expression "nonsystematic analysis" is used in this paragraph, based on the impressions of the authors of this work considering their patterns of consumption of media information on the subject. We are aware that this approach is not the most appropriate, and we also assume that content analysis studies will be published in the coming months to support or refute our opinions on how the media has dealt with the coronavirus issue during the first months of the pandemic.

\section{References}

Bae, Mikyeung (2018). "Understanding the effect of the discrepancy between sought and obtained gratification on social networking site users' satisfaction and continuance intention". Computers in human behavior, v. 79, pp. 137-153. https://doi.org/10.1016/j.chb.2017.10.026

Ball-Rokeach, Sandra J.; Defleur, Melvin L. (1976). "A dependency model of mass-media effects". Communication research, v. 3, n. 1, pp. 3-21.

https://doi.org/10.1177/009365027600300101

Baxter, Leslie A; Babbie, Earl (2004). The basics of communication research. Toronto: Thomson Wadsworth. ISBN: 0534 508367

Chen, Gina M. (2011). "Tweet this: a uses and gratifications perspective on how active Twitter use gratifies a need to connect with others". Computers in human behavior, v. 27, n. 2, pp. 755-762.

https://doi.org/10.1016/j.chb.2010.10.023 
Daries-Ramón, Natalia; Ferrer-Rosell, Berta; Cristóbal-Fransi, Eduard; Mariné-Roig, Estela (2018). “¿Postureo o disfrute de la experiencia gastronómica? Efectos de la reputación y la experiencia en la recomendación de los restaurantes de alto nivel". Cuadernos de turismo, v. 42, pp. 119-136.

https://doi.org/10.6018/turismo.42.05

Ezumah, Bellarmine A. (2013). "College students' use of social media: site preferences, uses and gratifications theory revisited". International journal of business and social science, v. 4, n. 5, pp. 27-34.

http://ijbssnet.com/journals/Vol_4_No_5_May_2013/3.pdf

Fisher, Robert J. (1993). "Social desirability bias and the validity of indirect questioning". Journal of consumer research, v. 20, n. 2, pp. 303-315. https://doi.org/10.1086/209351

Galinha, Iolanda-Costa; Pais-Ribeiro, José-Luis (2005). “Contribuição para o estudo da versão portuguesa da positive and negativeaffect schedule (Panas): II-Estudo psicométrico". Análise psicológica, v. 23, n. 2, pp. 219-227. https://doi.org/10.14417/ap.84

Galinha, Iolanda-Costa; Pereira, Cicero-Roberto; Esteves, Francisco (2014). "Versão reduzida da escala portuguesa de afeto positivo e negativo-Panas-VRP: Análise fatorial confirmatória e invariância temporal". Psicologia, v. 28, n. 1, pp. 50-62. https://doi.org/10.17575/rpsicol.v28i1.622

González-Vázquez, Alejandro; Igartua, Juan-José (2018). “¿Por qué los adolescentes juegan videojuegos? Propuesta de una escala de motivos para jugar videojuegos a partir de la teoría de usos y gratificaciones". Cuadernos info, v. 42, pp. 135-146. https://doi.org/10.7764/cdi.42.1314

Hayes, Andrew F. (2018). Introduction to mediation, moderation, and conditional process analysis, 2a ed. New York, NY: The Guilford Press. ISBN: 9781462534654

Hossain, Alamgir; Kim, Minho; Jahan, Nusrat (2019). “Can 'liking' behavior lead to usage intention on Facebook? Uses and gratification theory perspective". Sustainability, v. 11, n. 4, article 1166.

https://doi.org/10.3390/su11041166

Igartua, Juan-José (2006). Métodos cuantitativos de investigación en comunicación. Barcelona: Bosch. ISBN: 97884 97902717

Igartua, Juan-José (2015). “Psicología social de los medios de comunicación”. En: Sabucedo, José M.; Morales, J. Francisco. Psicología social. Madrid: Editorial Médica Panamericana, pp. 371-391. ISBN: 9788498359046

Igartua, Juan-José; Humanes, María-Luisa (2004). Teoría e investigación en comunicación social. Madrid: Síntesis. ISBN: 8497562267

Igartua, Juan-José; Rodríguez-De-Dios, Isabel (2016). “Correlatos motivacionales del uso y la satisfacción con Facebook en jóvenes españoles". Cuadernos info, v. 38, pp. 107-119.

https://doi.org/10.7764/cdi.38.848

Karapanos, Evangelos; Teixeira, Pedro; Gouveia, Ruben (2016). “Need fulfillment and experiences on social media: a case on Facebook and WhatsApp". Computers in human behavior, v. 55, pp. 888-897.

https://doi.org/10.1016/j.chb.2015.10.015

Katz, Elihu; Blumer, Jay G.; Gurevitch, Michael (1973). "Uses and gratifications research”. Public opinion quarterly, v. 37, n. 4, pp. 509-523.

Khan, Muhammad L. (2017). "Social media engagement: what motivates user participation and consumption on YouTube?". Computers in human behavior, v. 66, pp. 236-247.

https://doi.org/10.1016/j.chb.2016.09.024

Korhan, Orhan; Ersoy, Metin (2016). "Usability and functionality factors of the social network site application users from the perspective of uses and gratification theory". Quality \& quantity, v. 50, n. 4, pp. 1799-1816.

https://doi.org/10.1007/s11135-015-0236-7

Krcmar, Marina (2017). "Uses and gratifications: basic concepts”. In: Rössler, Patric; Hoffner, Cynthia A.; van Zoonen Liesbet. The international encyclopedia of media effects. Malden, MA: John Wiley \& Sons, pp. 1997-2009. ISBN: 9781118784044

LaRose, Robert; Eastin, Matthew S. (2004). "A social cognitive theory of Internet uses and gratifications: Toward a new model of media attendance". Journal of broadcasting \& electronic media, v. 48, n. 3, pp. 358-377.

https://doi.org/10.1207/s15506878jobem4803_2

Leung, Louis; Wei, Ran (2000). "More than just talk on the move: uses and gratifications of the cellular phone". Journalism \& mass communication quarterly, v. 77, n. 2, pp. 308-320.

https://doi.org/10.1177/107769900007700206 
McFadden, SarahAnn. M.; Malik, Amyn A.; Aguolu, Obianuju G.; Willebrand, Kathryn S.; Omer, Saad B. (2020). "Perceptions of the adult US population regarding the novel coronavirus outbreak". PloS one, v. 15, n. 4.

https://doi.org/10.1371/journal.pone.0231808

Papacharissi, Zizi; Rubin, Alan M. (2000). “Predictors of Internet use”. Journal of broadcasting \& electronic media, v. 44, n. 2, pp. 175-196. http://doi.org/10.1207/s15506878jobem4402_2

Phua, Joe; Jin, Seunga V.; Kim, Jihoon J. (2017). "Uses and gratifications of social networking sites for bridging and bonding social capital: A comparison of Facebook, Twitter, Instagram, and Snapchat". Computers in human behavior, v. 72 , pp. 115-122.

https://doi.org/10.1016/j.chb.2017.02.041

Potter, W. James (2013). “A general framework for media psychology scholarship”. In: Dill Karen E. The Oxford handbook of media psychology. Oxford: Oxford University Press, pp. 423-448. ISBN: 9780195398809

Quan-Haase, Anabel; Young, Alyson L. (2010). “Uses and gratifications of social media: A comparison of Facebook and instant messaging". Bulletin of science, technology \& society, v. 30, n. 5, pp. 350-361. https://doi.org/10.1177/0270467610380009

Rubin, Alan M. (2009a). "Uses and gratifications: an evolving perspective of media effects". In: Nabi Robin L.; Oliver, Mary B. Media processes and effects. Thousand Oaks, CA: Sage, pp. 147-159. ISBN: 9781412959964

Rubin, Alan M. (2009b). "The uses-and-gratifications perspective of media effects". In: Bryant, Jennings; Oliver, Mary B. Media effects: advances in theory and reserach. New York, NY: Rouledge, pp. 165-184. ISBN: 9780203877111

Sandín, Bonifacio; Chorot, Paloma; Lostao, Lourdes; Joiner, Thomas E.; Santed, Miguel A.; Valiente, Rosa M. (1999). "Escalas Panas de afecto positivo y negativo: validación factorial y convergencia transcultural". Psicothema, v. 11, n. 1, pp. 37-51.

Scherer, Helmut (2017). "Connecting media use to media effects". In: Rössler, Patric; Hoffner, Cynthia A.; Van Zoonen, Liesbet. The international encyclopedia of media effects. Malden, MA: John Wiley \& Sons, pp. 137-148. ISBN: 978 1 118784044

Sheldon, Pavica; Rauschnabel, Philipp A.; Antony, Mary G.; Car, Sandra (2017). “A cross-cultural comparison of Croatian and American social network sites: Exploring cultural differences in motives for Instagram use". Computers in human behavior, v. 75, pp. 643-651.

https://doi.org/10.1016/j.chb.2017.06.009

Sjöblom, Max; Hamari, Juho (2017). "Why do people watch others play video games? An empirical study on the motivations of Twitch users". Computers in human behavior, v. 75, pp. 985-996.

https://doi.org/10.1016/j.chb.2016.10.019

Terracciano, Antonio; McCrae, Robert R.; Costa Jr., Paul T. (2003). "Factorial and construct validity of the Italian positive and negative affect schedule (Panas)". European journal of psychological assessment, v. 19, n. 2, pp. 131-141.

https://doi.org/10.1027//1015-5759.19.2.131

Valkenburg, Patti M.; Peter, Jochen (2013). "The differential susceptibility to media effects model". Journal of communication, v. 63, n. 2, pp. 221-243.

https://doi.org/10.1111/jcom.12024

Vizcaíno-Laorga, Ricardo; Catalina-García, Beatriz; López-De-Ayala-López, María-Cruz (2019). “Participación y compromiso de los jóvenes en el entorno digital. Usos de las redes sociales y percepción de sus consecuencias". Revista Latina de comunicación social, v. 74, pp. 554-572.

http://doi.org/10.4185/RLCS-2019-1345

Wang, Chuang; Lee, Matthew K; Hua, Zhongsheng (2015). "A theory of social media dependence: evidence from microblog users". Decision support systems, v. 69, pp. 40-49.

https://doi.org/10.1016/j.dss.2014.11.002

Wang, Cuiyan; Pan, Riyu; Wan, Xiaoyang; Tan, Yilin; Xu, Linkang; Ho, Cyrus S.; Ho, Roger C. (2020). “Immediate psychological responses and associated factors during the initial stage of the 2019 coronavirus disease (Covid-19) epidemic among the general population in China". International journal of environmental research and public health, v. 17, n. 5, p. 1729. https://doi.org/10.3390/ijerph17051729

Watson, David; Clark, Lee A.; Tellegen, Auke (1988). "Development and validation of brief measures of positive and negative affect: the Panas scales". Journal of personality and social psychology, v. 54, n. 6.

https://doi.org/10.1037/0022-3514.54.6.1063 